\title{
Safe To Play ${ }^{1}$
}

\section{Pauline Oliveros}

What makes a place feel safe? Where is it safe to play? Who is it safe to play with? These questions cannot necessarily be answered by a law. The United Nations Convention on the Rights of the Child (UNCRC) has helped in many ways to promote safety for children and bring consciousness to the value and necessity of safety for children, but the child has to feel safe in order to play and to have a healthy life.

We come into the world ready to play. Improvising with babies is one of my favorite things. Baby makes a sound, I sound back in kind, and we are off! I was having great fun improvising with an eighteen-month-old baby one afternoon before a concert that evening. The parents brought the baby to the concert. About mid-way during the piece I was vocalizing much like I had in the afternoon session with the baby. Soon I heard a little voice coming from the audience. Sure enough my baby friend was vocalizing with me and on her way to the stage with parents in pursuit.

The child felt safe and ready for unrestrained play. She recognized the safe zone of play from the afternoon we had together.

Improvisation implies some kind of relationship with play. A child can play alone, with or without things, or with an imaginary or real friend. The primary plaything is voice. There are no rules for primary improvisation. The baby is free to vocalize and explore the depths of emotion. Voice is power. Communication with sound is real. Baby expresses needs vocally way before learning language. A loud shriek of frustration is unmistakable if one is listening. Sounds are the language of emotions. My baby friend expressed the joy of play as we engaged in it spontaneously. Play is improvisation and improvisation is play.

The imposition of rules for play creates the many games and styles that we experience in life. Rules also make it possible to be wrong and unsafe. The ability to learn and follow rules can also bring a sense of safety and accomplishment provided that the rules are understood and taught in a loving way.

The primary improvisation that I do with babies involves starting with their sounds and repetition. They seem to love being understood this way. The play gradually evolves with small changes. It is something like peekaboo. The play session usually continues for a long time. Sometimes more than an hour. There is great attention and fun.

Primary improvisation cannot be legislated; however, it can be recognized as a way to bring about happiness and relationship in accordance with the Preamble of the UNCRC:

Recalling that, in the Universal Declaration of Human Rights, the United Nations has proclaimed that childhood is entitled to special care and assistance,

Convinced that the family, as the fundamental group of society and the natural environment for the growth and well-being of all its members and particularly children, should be afforded the necessary protection and assistance so that it can fully assume its responsibilities within the community,

Recognizing that the child, for the full and harmonious development of his or her personality, should grow up in a family environment, in an atmosphere of happiness, love and understanding,

Considering that the child should be fully prepared to live an individual life in society, and brought up in the spirit of the ideals proclaimed in the Charter of the United Nations, and in particular in the spirit of peace, dignity, tolerance, freedom, equality and solidarity . . .

In the 1970s, I composed Sonic Meditations a group of pieces that departed from the prevailing new music paradigm that was full of rules, systems, and virtuosity. I was concerned with how to compose inclusive pieces that anyone could perform. Here is my introduction to Sonic Meditations:

I have abandoned composition/performance practice as it is usually established today for Sonic Explorations which include everyone who wants to participate. I attempt to erase the subject/object 
or performer/audience relationship by returning to ancient forms which preclude spectators. I am interested in communication among all forms of life, through Sonic Energy.

I am especially interested in the healing power of Sonic Energy and its transmission within groups. All societies admit the power of music or sound. Attempts to control what is heard in the community are universal. For instance, music in the church has always been limited to particular forms and styles in accordance with the decrees of the Church Fathers. It was forbidden for instance to notate or transmit the Allegri Miserere until the fourteen-year-old child Mozart transcribed the piece from memory and performed it outside of the church. Music in the courts had been controlled through the tastes of patrons such as Prince Esterhazy for the symphonies of Haydn. Today Muzak is used to increase or stimulate consumption in merchandising establishments.

Sonic Meditations are an attempt to return the control of sound to the individual alone, and within groups especially for humanitarian purposes; specifically healing. Each Sonic Meditation is a special procedure for the following:

1. Actually making sounds

2. Actively imagining sounds

3. Listening to present sounds

4. Remembering sounds

Because of the special procedures involved, most all of the meditations are available to anyone who wishes to participate regardless of-or in spite of-musical training. All that is required is a willing commitment to the given conditions.

Sound making during the meditations is primarily vocal, sometimes hand clapping or other body sounds, sometimes using sound producing objects and instruments.

Sound imagining is encouraged through the use of various questions designed to trigger auditory fantasy. Individuals are then asked to share what was heard inwardly with members of the group, using any means to describe the experience.

For example: What sound reminds you of home?

If you have heard your sound internally turn and share it with a neighbor.

Conditions given for listening to present sounds are intended to expand awareness of the auditory environment, both inside and outside of the individual.

For example: Forget about language and speech for a few minutes and just listen globally for all that is sounding in this environment.

OK now take a minute to remember and share what you heard with a neighbor.

Auditory memory is also encouraged by trigger questions with subsequent sharing of these memories in the group.

What was the first sound that you heard this morning? Share that with a neighbor.

Some of the meditations involve body movement as well.

Take a nice stretch right now!

The term meditation is used simply to mean dwelling with or upon an idea, an object, or lack of object without distraction, or divided attention.

For example we can try my first Sonic Meditation - Teach Yourself to Fly, dedicated to Amelia Earhart.

First get centered with your feet flat on the floor, back straight, head right over your shoulders, elbows heavy. I will read the instructions for Teach Yourself to Fly first then I will prompt each section as you perform: 
Begin by simply observing your own breathing. Always be an observer. Gradually allow your breathing to become audible, gradually allow your vocal cords to vibrate in any mode which occurs naturally without speaking or singing. Allow the intensity to increase very slowly. Continue as long as possible naturally until there is peak intensity of sound, stop when all others are quiet, always observing your own breath cycle.

Healing can occur in relation to the above activities when:

1. Individuals feel the common bond with others through a shared experience

2. When one's inner experience is made manifest and accepted by others

3. When one is aware of and in tune with one's surroundings

4. When one's memories, or values, are integrated with the present and understood by others

In process a kind of music occurs naturally. Its beauty is not through intention, but is intrinsically the effectiveness of its healing power. This may be felt by the group, and the music relates to the people who make it through participation and sharing, as a stream or river whose waters offer refreshment and cleansing to those who find it.

Sonic Meditations seems to resonate with the principles of the UNCRC. At least the pieces provide ways to play with sound and enjoy relationship with others in a non-critical way that does not require years of training or virtuosity. Rather what is trained by the doing is attention to sound, sounding, silence, listening, and relationship. Sonic Meditations led twenty years later to Deep Listening (1988).

Deep Listening ${ }^{\circledR}$ is a multi-dimensional practice created with the intention of heightening awareness of sound and sounding to connect profoundly with sensations, feelings, memories, and dreams. The ultimate intention is the expansion of consciousness of listening; learning the difference between listening and hearing; and focal and global attention using meditation, energy work, and creative play.

The name Deep Listening occurred to me after recording in a cistern with a forty-five second reverberation time. In order to play in this environment we had to take our instruments down a fourteen foot ladder through the one man sized opening. Recording was an afterthought that resulted in the release of Deep Listening by New Albion Records in 1989, and the formation of the Deep Listening Band. We thought that Deep Listening was a good title for the CD and band since we were incurable punsters, and there we were recording deep underground.

The first Deep Listening Retreat occurred in 1991 with twenty people sharing a week of sonic exploration and listening meditation. By then I had understood that indeed there was something to explore with Deep Listening. Hearing was understood fairly well with many scientific studies and writings, but listening barely had a definition.

After a week of listening meditation and sonic exploration, the twenty participants each composed their own pieces and performed them. They also noted a sense of community that is still operating today among many-thirty-four years later-from the intensity of that experience.

A zone of safety had been created for a group of twenty people with and without musical training to improvise and compose from their experience of listening. Adults, like children, need to feel safe to play. Safety is the knowledge that you have been heard and freedom from prejudice or undue judgment and criticism.

More often than not the word Listen! is a demand for attention. Listening may be hearing plus attention according to auditory neuroscientist Seth Horowitz. There is still some mystery to explore about listening.

So far there are few scientific studies on listening. These studies usually are about comprehension of speech. Deep Listening explores listening globally for the whole field of sound internally and externally. This means opening and including everything possible to hear without prejudice, judgment, analysis, or criticism. This is clearly opposite of our tendency to constantly engage in thinking, planning, and predicting, and shutting out the everyday or surrounding sounds.

Deep Listening also explores focal or exclusive listening or attention to detail or a stream of sound such as speech or music. What is most important is listening to listening, or understanding how you are using your attention to what you are hearing. 
Let's end with two thirty-second listening meditations:

- As we listen particles of sound decide to be heard. Listening affects what is sounding in symbiotic relationship.

- As we listen the environment is enlivened by what I call the listening effect.

- $\quad$ Can we make our listening a safe zone, a place where the children of the world will feel safe to play?

Thank you.

\section{Notes}

${ }^{1}$ Keynote address for the "Just Improvisation: Enriching child protection law through musical techniques, discourses and pedagogies" Symposium, Queen's University Belfast, 29 - 30 May 2015. For video documentation of the keynote, see <http://translatingimprovisation.com/portfolio/symposium>.

\section{Works Cited}

Horowitz, Seth. The Universal Sense: How Hearing Shapes the Mind. Bloomsbury, 2013.

Oliveros, Pauline. Sonic Meditations. Smith Publications, 1974.

United Nations Convention on the Rights of the Child (UNCRC). 